Louisiana State University

LSU Digital Commons

Faculty Publications

Department of Oceanography \& Coastal

Sciences

4-24-2012

Sustainability: More About The Toolmaker Than The Tools

R. Eugene Turner

Follow this and additional works at: https://digitalcommons.Isu.edu/oceanography_coastal_pubs

Part of the Oceanography Commons 


\title{
Sustainability: More About the Toolmaker than the Tools
}

\author{
R. Eugene Turner
}

\begin{abstract}
A sustainable system is not necessarily a high-quality one, but it could be. We could, for example, "survive" on the desperate edge, as the remnants in a self-fouled and deteriorating environment. Why won't a future sustainable system be just another industrial model of mass efficiency and throughput? Perhaps the incompatible outcomes are a choice between the sometimes nearly invisible civilizing aspects of culture nurturing respect, equality, and cooperation on one hand, and the greed and self-indulgences undermining social tolerance, empathy, and cooperation that ends up promoting violence and dehumanization. The human heritage is subtle, indestructible, and worth nurturing if we want that hospitable sustainable system. But, assuming that a kind of social osmosis will be sufficient to sustain justice and fairness is wrongheaded and dismisses the historical examples. A new cultural narrative is needed to override the maladaptive dissonance preventing formation of sustainable systems. This narrative will be anchored in personal initiatives, incorporates an appreciation of our evolved heritage, and is informed by intentional social learning within groups and occasional social punishment.
\end{abstract}

Keywords Humane sustainable systems • Cooperation • Altruism • Social learning - Governance • Societal behavior

\section{Our Heritage}

A Talmudic saying: "No one is the owner of his instincts; but controlling them, that is civilization" (Elie Wiesel, New York Times, 21 May 2011).

\footnotetext{
R.E. Turner $(\bowtie)$

Department of Oceanography and Coastal Sciences, Louisiana State University, Baton Rouge, LA 70803, USA

e-mail: euturne@1su.edu
} 
When human beings lose their connection to nature, ... then they do not know how to nurture their environment healing our society goes hand in hand with healing our personal, elemental connection with the phenomenal world (Chögyam Trungpa, Founder, Naropa University).

Imagine looking through the windows of your building and seeing something move on the prairie-yes, just over there. Maybe you can see the First Nation hunter put on a wolf or buffalo skin? He crawls for hours through the Blue Stem prairie under a hot sun collecting cat burrs in his hair, breathing dust, and accumulating small nicks to his skin as he follows the ambling bison herd (Fig. 1). The hunter

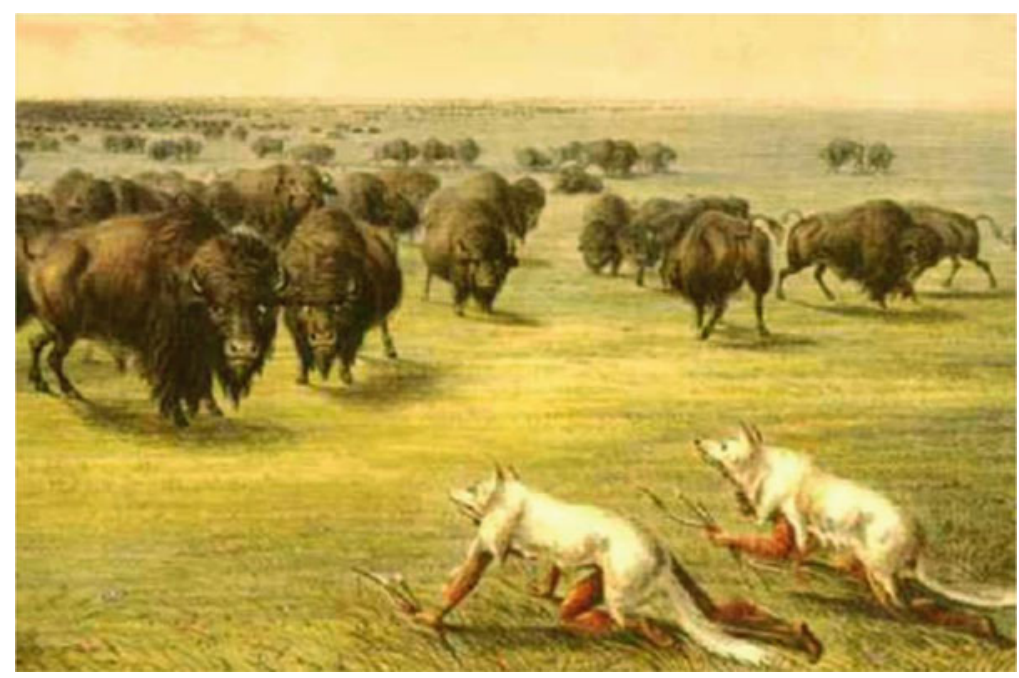

Fig. 1 "Buffalo Hunt in Wolf Masks" by George Catlin (1832) in the upper Missouri River (Original Painting held in Smithsonian American Art Museum, Washington, DC)

wants to be near a skittish 2,000-lb bull that could easily kick the femur out of his skin, or rumble away with 5,000 other buffalo_-all because a hawk screeches. The hunter might use a bow and arrow at $3 \mathrm{~m}$, or perhaps he puts a short spear through the animal's tough underbelly-it is a strong thrust under the ribs and into the soft heart. He twists and rams it in and out rapidly using both hands, draining the cardiac pump of its life force. The animal bellows, falls to its knees and then on its side, heaves a last breath, and stares at the sky. The hunter makes sure that the bull is dead then gives thanks, and washes in a creek, being mindful of what has just happened. There is a grassy-dry-matted-furred buffalo-coat smell to the hide as flies land on the dried blood. The carcass is processed on site. There is food for a week and raw materials for clothing and tools.

This day was once part of living closely, and deeply, within the natural world. There are no buffalo herds roaming the Plains today and the trails are straight and paved. Brick and lumber frame the windows you are looking through. There are 
electrical wires behind the walls. Was this a mirage? Did it really happen? If it did happen, then what remains?

Our hominoid ancestors may have been forest dwellers 6-8 million years ago, and Homo sapiens as early as 200,000 years ago, and most likely originating in Africa. ${ }^{1}$ They came to North America 10,000 years ago-that is, about $600-700$ generations ago. The senses were used and appreciated to survive, and not just survive, but to form communities with relationships that could be quite touching. The Neanderthals, for example, buried their dead in a grave of flowers. People thanked their animated world for blessings, painted cave walls with graceful imagery (Fig. 2), and had a sense of proportion and color and design in their clothing and cook ware. Cloth reminders were hung on trees to recognize spirits in ways that seem strange to modern people. Yes, survival required hard work and risk and there were mortalities. Survival happened within the context of the whole set of experiences that were totally dependent on the physical and mental senses. It was fully a

Fig. 2 Three horses facing each other in a Chauvet Pont d' Arc cave painting. The sensuous lines, shading, and posture were drawn 30,000-32,000 years BCE. Source: $\mathrm{http}: / / \mathrm{www}$. metmuseum.org/toah/hd/ chav/hd_chav.htm

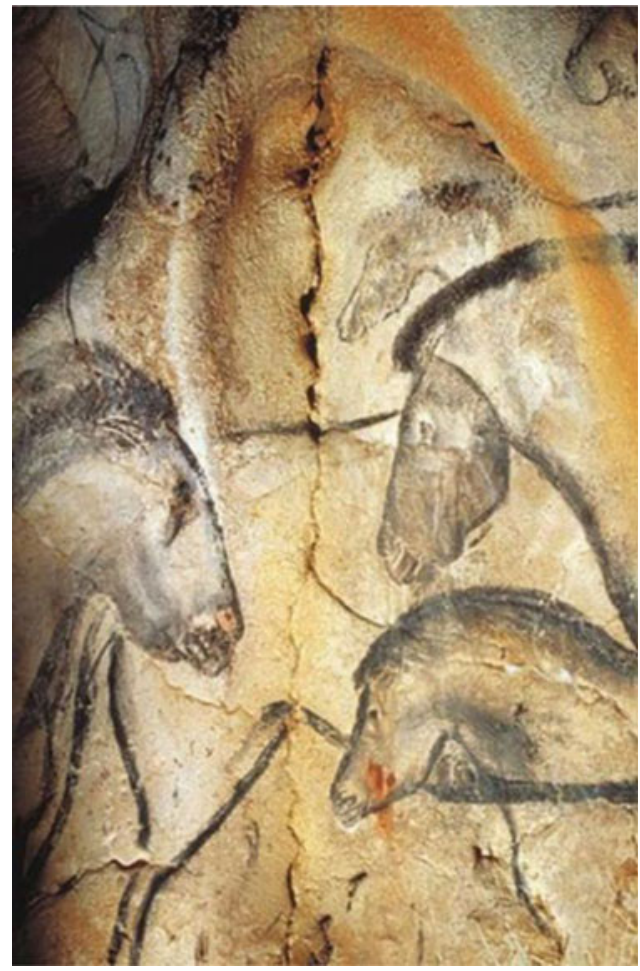

\footnotetext{
${ }^{1}$ Fossil records suggest modern humans emerged in sub-Saharan Africa about 200,000 years ago, but their dispersal is thought to have begun about 70,000 years ago and resulted in very little inbreeding with the Neanderthals. The earliest evidence of modern humans appears in Australia, dating to about 50,000 years ago.
} 
world of relationships that evolved from pre-existing relationships with animals and plants, and of the environment and its inhabitants. We have that legacy in our genes, our physical potential, and our neural networks. It is a set of pre-requisites inherited at conception and given potential at birth. It is unavoidably a part of us.

This inheritance should be considered the all of "you," because we don't acquire genetic traits rapidly. At 20 years per generation, our oil-based society of 100 years is five generations distant from the 5,000 to 10,000 generations since $H$. sapiens evolved and a few hundred thousand generations since Homo sp. showed up. Yet we have such little knowledge of this tethering to our past because of a constant set of diversions emphasizing a mere part of this inheritance. Our daily connections to the natural world are covered over so much that most of us don't know local birds, plant seasons, where milk comes from, the smell of different kinds of snow, of dirt, or of silence. We are, it seems, several trophic levels apart from the reality of food source, food preparation, and how to consume it while being fully present. The separations may seem to be about the external or physical world, but are carried within the mind of individuals and groups.

\section{Examples for Individuals}

It's not that we must return to some idyllic or imaginary past, but that we must appreciate that this heritage is within us, and that it has qualities to respect and nurture. But the nuances of those qualities may seem so invisible in modern life that they seem to not exist. Here are some examples of how that sometimes-subterranean legacy is exposed.

\section{Recovery from Gallbladder Surgery}

Ulrich (1984) examined the records of different groups of patients who had undergone gall bladder removal. The first group had a window view of a natural scene (trees) and the second group looked at a brick wall (Fig. 3). The two groups received the same post-operative medical attention and lived on the second and third floors of the same hospital wing. Their rooms were of similar dimensions and had one window. The first group recovered faster than the second group, with an average stay in the hospital of 8.0 days, compared to 8.7 days for the group looking at the brick wall. They received fewer negative evaluations by staff ( 1.1 vs. 4.0 per patient), and took fewer painkillers.

\section{Greenness and Psychological Health}

Other studies reveal how exposure to natural systems has a restorative effect on indicators of stress or well-being (Kaplan 1995; Ulrich 2007), including attention-deficit 


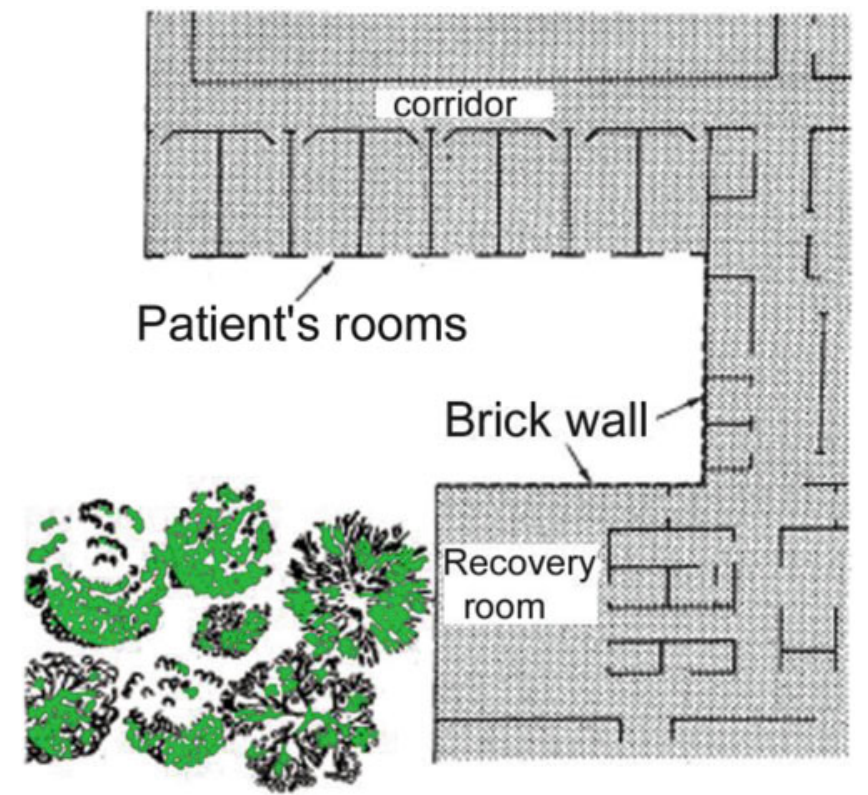

Fig. 3 The two views of patients undergoing gall bladder removal (Redrawn from Ulrich 1984)

activity (Kuo and Taylor 2004). Ulrich et al. (1991), for example, had 120 subjects view a stressful movie, and then exposed them to six different natural and urban settings while monitoring changes in various indices of stress (e.g., blood pressure, heart rate, muscle tension, skin conductance). Recovery was faster and more complete when subjects were exposed to natural rather than urban environments. The natural setting was accompanied by sustained attention. Taylor et al. (2001) found that inner-city girls (and interestingly, not boys) were positively affected by the naturalness of the view from their high-rise urban homes. For girls, the variance in test concentration, impulse inhibition, and delay of gratification was all directly related to their self-discipline, and $20 \%$ of that was related to the naturalness of the small natural setting near their home.

\section{Examples for Societies}

It was only a few hundred generations ago that our ancestors lived without written communication, having evolved to that state in intimate contact with the natural world by using all of their senses (Abram 1996) and in intimate social gatherings. They had to cooperate to survive and so it is easy to imagine that evolutionary pressures are involved to support cooperation and to dissuade maladaptive tendencies. Children, for example, spontaneously begin to demand fairness/equal treatment for 
others ("pro-sociality") between 4 and 7 years old, at the same time that their interest in fairness begins to favor their peers (Fehr et al. 2008). These and other inheritances are expressed in individual and group preferences. Their influence may be nuanced, for example, as in the innate aversion to unequal rewards for equal work by monkeys and dogs (Brosnan and de Waal 2003; Range et al. 2009). They may be complex, like the decisions affecting cooperation or defectors in group dynamics (Semmann et al. 2003); and they may be subtly hidden in the social matrix like the changes in altruism as population density rises (Levine 2003). The political behavior of chimpanzees and early human societies suggests that we have evolved to maximize our interactions at the small-scale, at the personal scale (de Waal 2007; Boehm 1999). Gandhi (1909) emphasized how the basic goodness and cooperative nature of people at this personal scale was the history of the world, and that the written formal history was a thin veneer of exceptions covering over these mostly invisible daily interactions.

This desire for fairness and equal access is one of the fundamental requirements for peaceful cooperation at the personal level and the group level. Wilkerson and Pickett (2009a, b) have illuminated the dozens of strong relationships between income inequality and social problems, including mental illness, incarceration rates, teenage pregnancy, illiteracy, obesity, drug abuse, and education performance (Fig. 4). The social stratification in income distribution reflects strong societal differences in material inequities permeating developed and underdeveloped countries. The lessons of history are that strong social inequalities cannot be sustained.

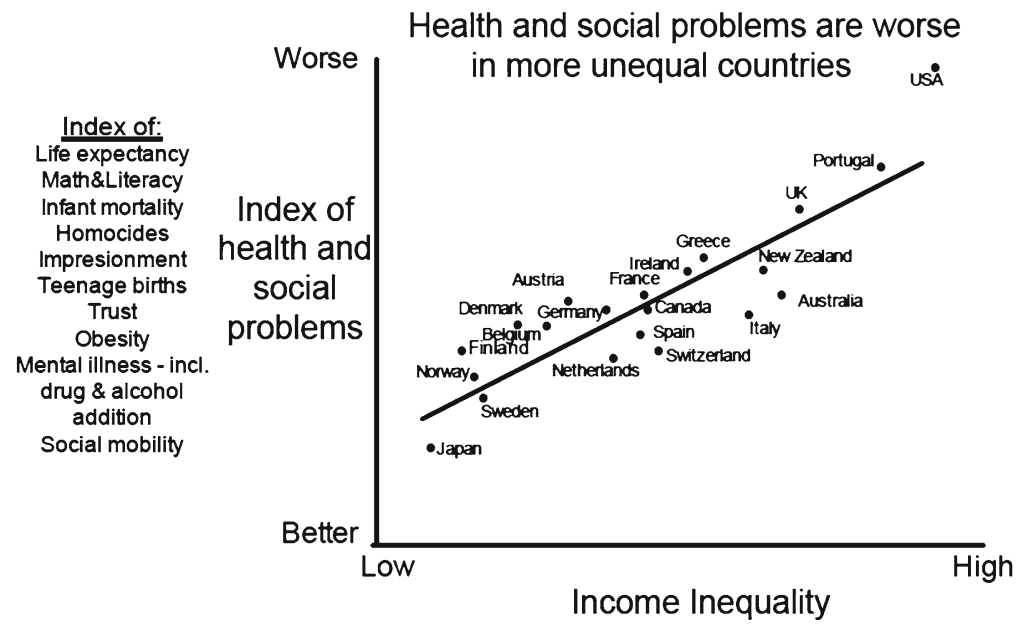

Fig. 4 There are many direct relationships between the scale of income disparity and negative social attributes that are discussed in Wilkerson and Pickett $(2009 a, b)$. This is one example (Redrawn from http://www.slideshare.net/equalitytrust/the-spirit-level-slides-from-the-equalitytrust) 


\section{Contrasting Options}

Sustainable systems, or nearly sustainable ones, existed in the New World before Europeans arrived. They were not static, and obviously did not successfully resist the more aggressive invaders intent on a growth economy whose wealth was distributed in a highly stratified society. Their social structure is an example that we might learn from as we re-invent our governance for the new conditions.

\section{Balinese Rice Farmers}

The Indonesian island of Bali has a water distribution network dependent on the rains whose amount is seasonal and dependent on elevation. J. Stephen Lansing studied this system for decades and wrote an outstanding summary of the linked geology, history, culture, and ecology of this resilient landscape as it was challenged in the modern era (Lansing 2007; Fig. 5). Water is distributed by a sys-

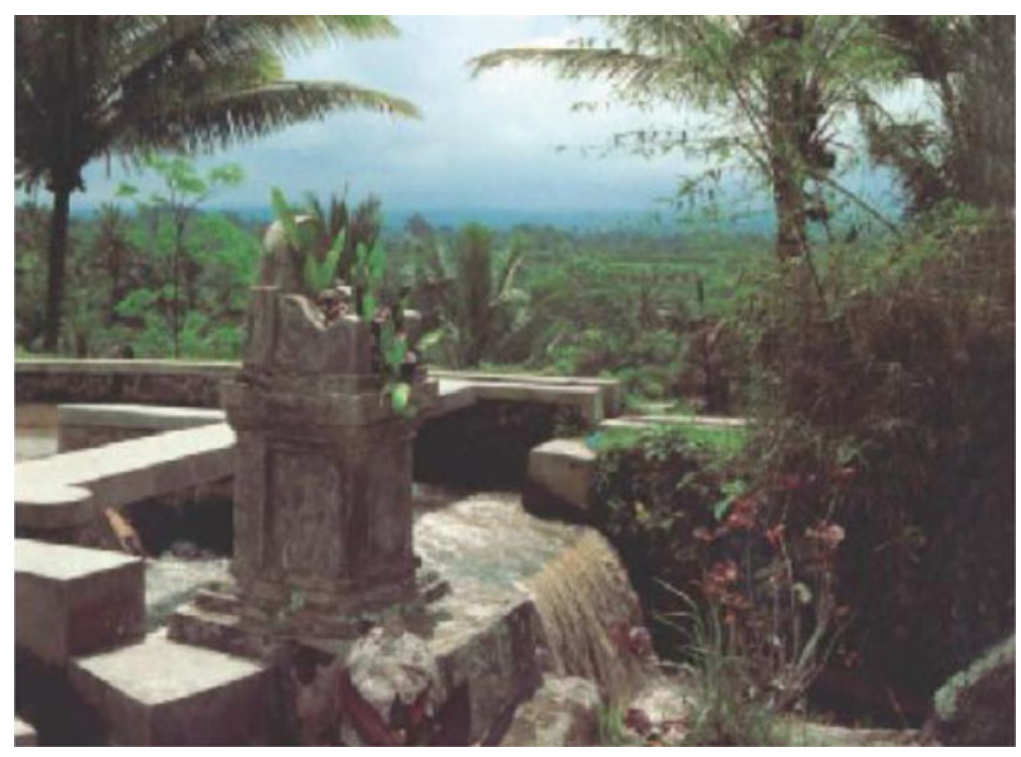

Fig. 5 The cover from Lansing's book "Priests and Programmers" illustrating a temple up the mountain that regulates water flow

tem of canals, tunnels, streams, and weirs. The availability of water determines the number and kinds of crops that are grown and pests. The pests come from adjacent fields and can be controlled by large-scale withdrawal of their habitat via drying fields and synchronous planting/harvest rhythms. So there is a kind of 
benefit-cost calculation made to control pests by timely and large-scale water withdrawal, and having water delivered for the crops. And this balancing was orchestrated by the temple priests who attentively dealt with the strictly agricultural, as well as the related social issues. To the Balinese, the relationship between the natural environment and the social environment were interdependent, and not linear. Effective management required cooperation across all watersheds, and even beyond. Lansing says that "essentially, water temples establish symbolic connections between productive groups and the components of the natural landscape that they seek to control. The natural world surrounding each village is not a wilderness but an engineered landscape of rice terraces, gardens, and aqueducts created by the coordinated labor of generations of predecessors. Anthropomorphic deities evoke this residual human presence in an engineered landscape."

The very success of the system kept it invisible to the colonial Dutch and then the post-World War II administrations. They were illuminated to the non-Balinese only in the early 1970s. It was then that the Green Revolution undercut the traditional cropping system in a way that resulted in competition for water and unresolved dissatisfactions, a patchwork of habitats harboring many pests that were never constrained, and poor harvests. The role the intricate and self-sustaining social network was eventually recognized and re-fortified, and the formerly invisible threads of cooperation was sanctified by bureaucrats who recognized a system that they could not do without. The top-down approach control structure was minimized and the bottom-up and integrated social network it harmed was being restored.

\section{Columbus}

The historian Howard Zinn (2003) describes Columbus as an excellent navigator and a brutal colonialist. He quotes the journals of a Christian priest (Las Casas) who said the Spaniards "thought nothing of knifing Indians by tens and twenties and of cutting slices off them to test the sharpness of their blades." Half of the 250,000 Indians on Haiti died within 2 years from murder, mutilation, or suicide. Las Casas estimated that "from 1494 to 1508 , over three million people had perished from war, slavery, and the mines. Who in future generations will believe this? I myself writing it as a knowledgeable eyewitness can hardly believe it." Columbus loaded 500 Awarak slaves on the return voyage from the Caribbean, and 200 died on the way.

These cultural atrocities attributed to Columbus were not the exception, of course. The English spread smallpox in woolen goods given to the Mi'kmaq of Nova Scotia (circa 1713) and the 24 Nov 1752 reward for their scalps was in effect for more than 200 years (Paul 2000). What is instructional, however, were the Native American societies existing in Columbus's time. The Awaraks had greeted him with a hospitality not found in Europe. They shared all they had with him, as they did with themselves. Zinn (2003) writes that: "Columbus and his successors were not coming into an empty wilderness, but into a world which in some places was as 
densely populated as Europe itself, where the culture was complex, where human relations were more egalitarian than in Europe, and where the relations among men, women, children and culture were more beautifully worked out than perhaps any place in the world." And that "they were people without a written language, but with their own laws, their poetry, their history kept in memory and passed on, in an oral vocabulary more complex than Europe's, accompanied by song, dance, and ceremonial drama. They paid careful attention to the development of personality, intensity of will, independence and flexibility, passion and potency, to their partnership with one another and with nature." Zinn (2003) says that that $2 \%$ of the population owned 95\% of the land in Europe, at the very time that there were sustainable societies of fairness and harmony in the New World. This is quite a contrast.

\section{Deganawidah}

Not all societies in the New World were in harmony, of course. The transformative agents that arose demonstrate that fundamental changes could occur within a generation and illustrate some of the elements that sustain their influence. Deganawidah was one of these influences. He was born to a Huron woman in what is now New York circa five centuries before Columbus arrived. The Huron were a warring tribe then and rejected his message of peace. Deganawidah left them to begin a pilgrimage that eventually united a confederation of Haudenosaunee tribes (the Great Iroquois Confederation), which the Huron eventually did join (Johansen and Mann 2000). Deganawidah was accompanied by Ayowenta ${ }^{2}$ who he rescued from both bitterness and cannibalism. ${ }^{3}$ Red Elk's description of Deganawidah's teachings (http://www.manataka.org/page1639.html) speaks of the Way of Great Peace, which taught the need for balance within society that began within the individual. When there was a balance of male/female within the individual, then peace expands out to the other gender, then to family, and eventually to other tribes. The tribe was governed as a living system of human consciousness for all, and was not focused on the individual. The decision matrix for the tribe was complex and inclusive. No individual, gender, or age group made a decision for the tribe. The males on the war councils could be removed by the Council of Grandmothers who may have nominated them. Further, the women made moccasins and so no war would last long without their support. Their governance structure and attitudes formed the basis for much of the Constitution of the United States and the US Declaration of Independence.

\footnotetext{
${ }^{2}$ Ayowenta is the Onondaga spelling of Hiawatha, who is not the imaginary person of H.W. Longfellow's poem.

${ }^{3}$ Ayowenta is sometimes also known as the "Translator" because of Deganawidah's presumed speech impediment.
} 


\section{Modern Analogues to Work with?}

An explicit societal effort is required to overcome those parts of our genetic inheritance that produces undesirable outcomes. The good news is that our inheritance also includes the indestructibly decent and desirable possibilities to do that. It is not that there are "bad behaviors" to be pushed away, but that we need to be inquisitively aware of them, lest they become manipulated by omission or active external influences. Here are two simple examples: (1) my experience in England, at times, is that people are expected to stand in a line when waiting on a bank teller, at a post office, or for a ticket. If someone ignores the line to squeeze ahead of others, then more than one person will tell them quite directly to "queue up," "take your turn, mate" or "we all want to get this done, just like you; now get to the back of the line." In other countries, there are sharp elbows and no line. It is a stronger social instruction if more than one individual responds; (2) there is a "social trap" that I use in class to discuss the social contract. It involves a mattress falling of the roof of a car blocking the road to the cars behind; the driver carrying the mattress does not realize that the mattress fell off, and continues on, but the mattress is now blocking the road. One option for the first driver behind the mattress now lying on the road is to wait for an opening in the oncoming traffic. This takes time and the traffic logjam in that lane grows as each driver sequentially finds the mattress blocking the path forward. It only takes one person to move the mattress to the side of the road so that everyone can continue without further delays.

\section{Viticulture}

Vineyards are ecosystems managed for decades. The producers are usually skilled, but I doubt that most think they know everything about making and marketing wine, or that there are no more surprises. Many vineyards are more than 100 years old, and are the result of transplanted expertise whose viticultural roots are perhaps thousands of years old. These vineyards and others in the world have formal and informal means to improve the harvest-governmental policies, extension agents, scientists, accountants, familial apprenticeships, and export-import industries. Developing and maintaining sustainable systems is hardly so simple or well evolved as vineyard management. But there are similarities. The interactions must evolve, there are external influences, and we tend to think of ecosystems as producers of something. Ecosystem management views are often subsumed by an economic view of the world, so a product-service relationship may be espoused. I think this is shallow view, but it is an influential view. And in the process of selling a product, society has often hypocritically promoted its abuse. There is often a great deal of hypocrisy, for example, with governmental and personal promotion/acceptance of the well-documented and unhealthy consequences from drinking and smoking for the consumer and those around them. 


\section{Smoking Laws}

The present restrictions on smoking in public spaces were difficult and took years to implement (and are not completely in place) despite an incredible array of research results, support from health professionals, and angry non-smokers. The tobacco industry executives did not go to the funerals of our relatives dying from emphysema. Those that went through the social change might recall the struggle to minimize the discomfort of telling our smoking friends that they could not smoke in our homes, or that we would not be able to socialize in "smoky" joints with them. Parents had to persuade children that it was not a "cool" behavior within the context of a torrent of advertising saying otherwise. And this was just a change in smoking laws, which seems like light work compared to what it will take to make the transition into sustainable systems!

\section{Wetland Protection}

Are there good predictors of success (and failure)? For example, what makes for a successful restoration program when viewed at a societal level? LaPeyre et al. (2001) addressed both of these questions in an interesting and straightforward way using a traditional scientific analysis, and with results that non-scientists might appreciate (Fig. 6). They conducted a statistical analysis of factors

\section{Dependent variable}

Environmental characteristics (quality)

Economic capital (\$ and productivity)

Government (political system index; inclusiveness)

Social capital (education, health; UNDP 1995)

Agricultural land pressure (\% agricultural land; = scarcity)

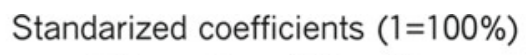

Fig. 6 A statistical analysis of factors influencing wetland protection and management in 90 nations (conventions, area, participation). The stronger the response, the more influence that factor has on environmental quality (Adapted from LaPeyre et al. 2001)

influencing wetland protection and management in 90 nations. The measure of success was an amalgam of several indicators of wetland protection, including the number of RAMSAR sites and when they received designation, the total wetland area protected, and the percentage of wetland area protected. Various social and economic factors were examined to see how much they influenced the dependent variable (wetland protection). The independent variables included national 
indices developed by others on: (1) social capital (e.g., health and education), (2) economic indicators (economic growth, trade, per capita earnings, investment), (3) governmental characteristics (various indicators of shared governance and openness), (4) environmental characteristics (air and water quality, government actions in protection treaties, and citizen participation), and (5) land pressure (primarily agricultural development).

The essential points of what they found are summarized in Fig. 6. The factors that had a positive influence on the quality of wetland protection and management were the quality of the environment, the openness and inclusiveness of government, the quality of the nation's social development, and, lastly, the expansion of agriculture. A negative influence was the degree of economic capitalization. I interpret these results as support for the following conclusions. First, the scarcity of wetlands brings appreciation for their losses and value, so that when agricultural expansion results in a regression of wetland area, then people and governments tend to respond with a heightened sense of the need for wetland protection/management. Second, this response is more likely to occur when citizens appreciate environmental quality and also have the means of responding. But this favorable response is more likely to happen when the governmental structure is receptive to these reactions through all types of interactions, including through local, regional, national, and non-governmental organizations. The negative relationship between wetland protection and indices of economic capital is due to the pressures for using the wetland area or capturing the social services of wetlands (a public benefit) for private gain. Greed, in other words, is not known as being an altruistic social attribute, or, to put it more benignly, economic activity is an imperfect measure of the general welfare.

My argument is that there are reciprocal interactions between environmental quality (hence sustainable systems), and the society's interests or appreciation for them. If social capitalization is necessary to initiate and sustain environmental quality, then isn't there a positive feedback between the health of society and its ecosystem (and I will leave the definition of "health" for the reader to interpret in their own situation-I am asking only for one to think about it)?

\section{Social Learning and Punishment}

Experiments and comparative analyses within and among cultures have unequivocally demonstrated that many individuals will be "fair" in situations when they have no recognizable benefit in terms of reproduction, food, economics, or status, and that they will punish unfairness. Perhaps paradoxically, the role of punishment is a positive influence on cooperation (punishment must not generate significant permanent counter-acting resentment), promotes social learning and supports institutions governing resources held in common (Sigmund et al. 2010). The drain of free riders (hitch hikers) is held in check, and the costs of punishment are outweighed by the increased gains from cooperation (Gächter et al. 2008), but only "if complemented by strong social norms of cooperation" (Herrmann et al. 2008). Social learning is, therefore, not entirely dependent on hereditary influences (Henrich et al. 2010). 


\section{The Edge of the Precipice}

It is not necessary to "go back" in time to be the kind of creature you are. The genes from the past have come forward to us. I am asking that people change not their genes but their society, in order to harmonize with the inheritance they already have (Shepard 1996).

This is already a crowded planet and getting warmer. There are 107 million $\mathrm{km}^{2}$ of habitable land on earth and seven billion people. That means that there are 1.53 ha ( $3.76 \mathrm{ac}$ ) per person. From that 1.5 ha per person come the materials for cell phones, cars and computers, trucks, cement, etc. The land is where people labor to provide the beans for a double-latte grande, wheat, flowers, fruits, and fructose. Energy reserves are dwindling and water is already re-cycled multiple times. If we are going to build sustainable systems that are desirable, then, based on the examples discussed, it will not be helpful to stratify the remaining resources further between haves and have-nots. Doing so is incompatible with our deeply social nature that is cooperative and that values fairness and equitability. This book is about building sustainable systems, which is to say that it is about social contracts.

A sustainable system does not have to be a pleasant one, but it could be. The science of sustainability brings clarity, and is absolutely essential to understand the qualities of managing coupled human-natural systems. But why will a sustainable system not be just another industrial model of efficiency, of mass throughput, and based on mass survival, but not quality? Can't a dictatorial social system with a stratified social structure survive for quite awhile? Or will it eventually fail because the social contract between individuals is unenforceable? We expect quality in our sustainable systems, but that will not happen, I think, without a pervasively ubiquitous and conscious effort at the individual level, which is what the Great Iroquois Confederation - just one example of many-was all about.

The dissociation of the individual from the natural world is continuing (Pergams and Zaradic 2008) and it has consequences. We can and must acknowledge and work with that disconnection at the personal level to be helpful working within society. I am not arguing, however, to recreate harsh environments, but to respect the human aspects that supported the genetics, or that the genetics gave life to. I think it a reasonable hypothesis, therefore, that the restoration of a few hectares of habitat is, potentially at least, also about societal renewal and health. In the process of restoring ecosystems, individuals and society are re-establishing their relationships with the larger environments they live in, depend upon, learn from, and which many believe must be nurtured if the much-used term "ecosystem sustainability" has meaning.

This is not going to be easy and we are working against our evolutionary nature in some ways. We spent our evolutionary path, for example, trying to find satisfactory food that tastes good. We now have it at every corner, and many of us are obese. I am not saying to stop eating. We ambled along our evolutionary walk gaining some predictability over food supplies, and now we have the "Dead Zone" at the end of the Mississippi River created as a result of land use practices in an industrialized agricultural landscape. We can put "culture" back in agriculture. We have 
an irrepressible-or nearly so-interest in procreating. I am not saying that sex is bad or should be stopped, but that sexual relationships are not automatically isolated from the love in relationships and the touching and constructive emotional content. We once lived in humility, and community respect-and it occasionally became unbalanced. I am not saying that there were not outrageous consequences of unbalanced behavior, but to see that there were also times in history, in our culture, in our life, when things are kinder and gentler. We still have the capability and unbroken human traits of kindness, dignity, and lightness within that survived the bad times, and nurtured good behaviors. I am arguing to see these good aspects clearly and to nurture them actively. Indulgence in ignorance is not a positive attribute, although it may accelerate economic exchange. We have gone forth and multiplied and now have dominion over the earth in many ways. Now what? How will the tension between unbridled individual action (e.g., in economic markets), be resolved to make space for the necessary and dominate collective agreements (e.g., for climate change)? It usually seems like addressing that is a huge mystery to me, but that is not the same as saying it is impossible or undoable or unnecessary. It must include nurturing the innately human social abilities we all have. But we need a new cultural narrative to replace existing ones. It means to open some baggage, to know what is inside, and to be willing to be surprised. The dictums of good behavior and attributes still apply - and must apply one by one, every day, by every person, and together.

\section{The Wabash Rule of 22}

The movie "Shakespeare in Love" has a scene in which the introduction of Shakespeare's newly completed "Romeo and Juliet" is done by Wabash. Wabash is a nervous character with a terrific stutter and can barely complete a word, much less a sentence. If the play fails this first performance, then the theater is closed. Wabash is the edge of a calamity. Henslowe thrusts Wabash onstage where he gathers himself in a temporary stutter and then ... launches into a brilliant and flawless introduction. He speaks clearly and his sentences flow from one to another with pizzazz and energy that reveals a sincere joy for the play. The audience gives boisterous response and the cast is inspired as it explodes into action. William $\mathrm{S}$, however, expected a disaster and is now confused. He asks Henslowe: "What happened? Henslowe pauses, and then looks straight at him: "It is a mystery" and then turns to continue managing the performance.

Entire cultures are now unsure about their human heritage. When we dismiss this heritage intentionally or by omission, then we won't have the sustainable planet we aspire to live in. The reality is that unless we recognize that our common collaborative heritage is sufficient, and that we are whole, then a desirable sustainable system is not possible. Here is one way to look at it. A social worker in Quebec told me that there were 22 people compromised by an addictive behavior. The addiction might be an alcohol, heroin, or sex, and the 22 people were generally those closest to the 
addicted person who was unwilling to confront either the addiction its consequences. We can use the same empiricism to construct what happens when a positive example ripples through society to reach 22 people in a constructive way. And if one is skillful, then it will be multiples of 22. Our heritage may be a buried mystery, but it can be partially known, appreciated and nurtured. We cannot know everything, but we can be part of the theater, participate with enthusiasm, move beyond our fear of stuttering, and deliver our lines with authenticity and with effect. It may or may not be a disaster, but it is the only 'theater' we have, - our only home, our only life, and sole opportunity.

Acknowledgments I thank Mike Weinstein for the encouragement here and in previous collaborations leading up to this effort. I first explored this topic in Matfield Green, KS, at the 2005 Graduate Student Fellowship meeting of the Land Institute (Wes Jackson, Founder). Any inadequacies found herein, however, are the consequence of being a poor student-a "bug" in the web of this life, who has been incredibly fortunate to have experienced inspiring examples in the natural world, benefited from readings, ordinary life with others, and had precious encounters with profound teachers. Financial support was provided by NSF award DEB1008184.

\section{References}

Abram D (1996) The spell of the sensuous. Random House, New York

Boehm C (1999) Hierarchy in the forest: the evolution of egalitarian behavior. Harvard University Press, Cambridge

Brosnan SF, de Waal FBM (2003) Monkeys reject unequal pay. Nature 425:297-299

De Waal F (2007) Chimpanzee politics: power and sex among apes. Johns Hopkins University Press, Baltimore

Fehr E, Bernhard H, Rockenbach B (2008) Egalitarianism in young children. Nature 454:1079-1083

Gächter S, Renner E, Sefton M (2008) The long-run benefits of punishment. Science 322:1510

Gandhi MK (1909) Hind Swaraj or Indian home rule. Navajivan Publishing House, Ahmedabad (Re-published in 1938)

Henrich J, Ensminger J, McElreath R et al (2010) Markets, religion, community size, and the evolution of fairness and punishment. Science 327:1480-1484

Herrmann B, Thoni C, Gachter S (2008) Antisocial punishment across societies. Science 319:1362-1367

Johansen BE, Mann BA (eds) (2000) Encyclopedia of the Haudenosaunee (Iroquois Confederacy). Greenwood, Westport

Kaplan S (1995) The restorative benefits of nature: toward an integrative framework. J Environ Psych 15:169-182

Kuo FE, Taylor AF (2004) A potential natural treatment for attention-deficit/hyperactivity disorder: evidence from a national study. Am J Public Health 94:1580-1586

Lansing JS (2007) Priests and programmers: technologies of power in the engineered landscape of Bali. Princeton University Press, Princeton

LaPeyre M, Mendelssohn IA, Reams MA et al (2001) Identifying determinants of nation's wetland management programs using structural equation modeling: an exploratory analysis. Environ Manage 27:859-868

Levine RV (2003) The kindness of strangers. Am Scient 91:226-233 
Paul DN (2000) We were not the savages. Fernwood, Halifax

Pergams ORW, Zaradic PA (2008) Evidence for a fundamental and pervasive shift away from nature-based recreation. Proc Nat Acad Sci USA 105:2295-2300

Range F, Horn L, Viranyi Z, Huber L (2009) The absence of reward induces inequity aversion in dogs. Proc Nat Acad Sci 106:340-345

Semmann D, Krambeck HJ, Milinski M (2003) Volunteering leads to rock-paper-scissors dynamics in a public goods game. Nature 425:390-393

Shepard P (1996) The only world we've got: a Paul Shepard reader. San Francisco Books, Sierra Club

Sigmund K, De Silaa H, Traulsen A, Hauert C (2010) Social learning promotes institutions for governing the commons. Nature 466:816-863

Taylor AF, Kuo FE, Sullivan WC (2001) Views of nature and self-discipline: evidence from inner city children. J Environ Psychol 21:1-15

Ulrich RS (1984) View through a window may influence recovery from surgery. Science 224: $420-421$

Ulrich RS (2007) Visual landscapes and psychological well-being. Landscape Res 4:17-23

Ulrich RS, Simons RF, Losito BD et al (1991) Stress recovery during exposure to natural and urban environments. J Environ Psych 11:201-230

Wilkerson RG, Pickett K (2009a) Income inequality and social dysfunction. Ann Rev Sociol 35:493-511; http://www.equalitytrust.org.uk/

Wilkerson R, Pickett K (2009b) The spirit level: why greater equality makes societies stronger. Bloomsbury Press, London http://www.slideshare.net/equalitytrust/the-spirit-level-slidesfrom-the-equality-trust

Zinn HA (2003) A people's history of the United States: 1492-present. Harper Collins, New York 